\title{
BILATERAL OPTIC ATROPHY AFTER VACCINATION AGAINST THE COMMON COLD*
}

\author{
BY \\ JENS EDMUND AND ERIK GODTFREDSEN \\ University Eye Clinic and Bispebjerg Hospital, Copenhagen
}

THE retina and optic nerve are frequently the seat of pathological reactions caused by toxic agents of different types. The affection of the optic nerve may be due to the absorption of external poisons and thus result in a toxic amblyopia such as the wellknown tobacco-alcohol amblyopia, or it may be caused by endogenously elaborated toxins. While most of these clinical pictures are obviously toxic in their nature, other manifestations of a definite allergic character sometimes occur. Generally allergic reactions in the retina and the optic nerve seem to follow the usual allergic pattern of reaction, although the optic nerve deviates from this in the rare instances of allergic optic neuritis (Theodore and Schlossman, 1958). In such cases the allergic reaction may appear as a papillitis with or without retinal oedema or as a retrobulbar neuritis.

In the study of apparently primary optic atrophies (Edmund and Godtfredsen, 1963), a case has recently been observed in which the history indicated that the apparently idiopathic optic atrophy was the result of an allergic reaction. Although such a manifestation occurs extremely rarely, the present case is reported as an example of an unnecessarily induced anaphylaxis.

\section{Case Report}

A 55-year-old male was referred to the neurological department of Bispebjerg hospital with increasing visual loss in both eyes. There was no family history of eye disease. There had been a slight cranial trauma 7 years ago, with no signs of concussion. There was no abuse of tobacco or alcohol. The patient had enjoyed good health and good vision. He had held a driver's licence since 1926, and his vision had last been tested on renewal of the licence 2 years ago. During the last 6 months he had had increasing trouble with reading, which could not be improved with glasses.

A general and neurological examination showed nothing abnormal. Height: $174 \mathrm{~cm}$. Weight: $100 \mathrm{~kg}$. Blood pressure: 160/100. Erythrocyte sedimentation rate: $2 \mathrm{~mm}$. Haemoglobin: $16 \mathrm{~g}$. per cent. Urine: negative. Blood and cerebrospinal fluid Wassermann reactions: negative. $X$ ray of thorax: normal.

The optic media and anterior segments were normal. The visual acuity was $6 / 36$ in the right eye and 6/18 in the left, not improved with glasses.

Ophthalmoscopy showed that both discs were pale and atrophic, the right more than the left, with no cupping or excavation, and no displacement of the vessels. A delicate stippling of the peripapillary tissue and perivascular sheathing of the vessels, indicative of secondary atrophy, were noted on both sides. The vessels were sclerotic with Gunn's phenomena but there was no extravasation.

The visual fields showed an enlarged blind spot on both sides with constriction of the nasal field (Figure, opposite).

A central scotoma which was present at the first examination disappeared later. The tension was $10 \mathrm{~mm}$. (applanation tonometer). The water-drinking test was normal. Gonioscopy showed open angles. Arteriography and encephalography revealed nothing abnormal. After the pneumo-

\footnotetext{
* Received for publication March 4, 1964
} 

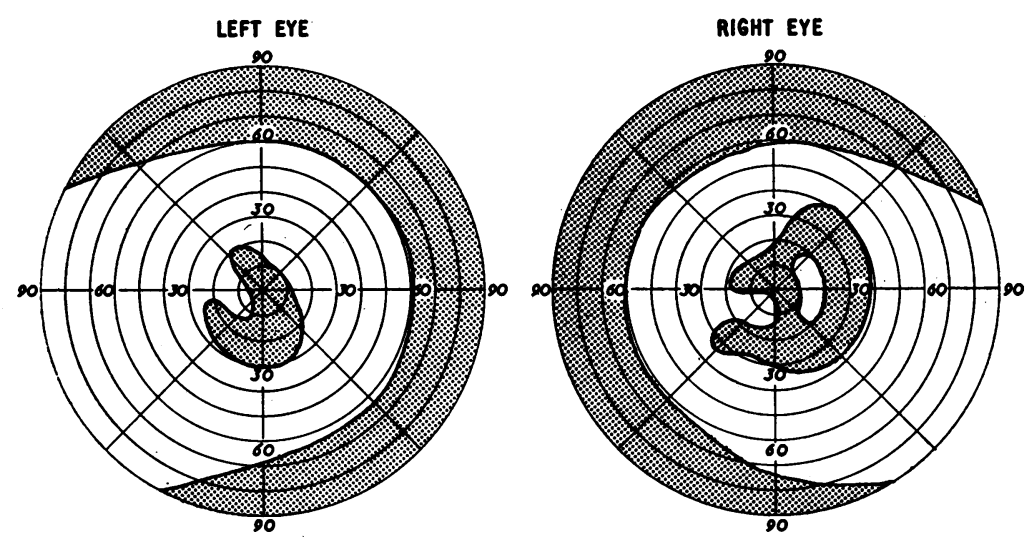

encephalography the patient reported visual improvement in the left eye, and the vision was found to be 6/9. Electro-encephalogram normal. Serum $B_{12} 440$ (normal).

A careful reconsideration of the history then revealed that 2 years before the patient had been vaccinated against the common cold, with the usual mixture of streptococci, staphylococcus, pneumococcus, Micrococcus catarrhalis, and Pfeiffer's bacillus. There had been no ill-effects from the first and second injections, but immediately after the third injection he began to feel unwell and an anaphylactic shock developed, so that he collapsed and fell to the floor. The body temperature was high, and he was confused and atonic and had to stay in bed for a week. He did not remember whether the vision was reduced at that time, but he had made a complete recovery after one week.

\section{Discussion}

The history excludes tobacco and alcohol amblyopia, and according to the findings and provocative test glaucoma can be left out of account. A heredofamilial optic atrophy of the Leber type is unlikely as the patient is the thirteenth of a family of brothers and sisters with no eye disease, and his condition manifested itself comparatively late in life. The slight head trauma occurred 7 years ago, but there was no evidence of neurological disease or intracranial abnormality: The only clue in the history since his vision was tested 2 years before is the anaphylactic shock which followed the third injection of vaccine against the common cold.

It is well known that a minor leptomeningitis might occur in connexion with such an allergic reaction; Kennedy (1938) noted the occurrence of serum sickness with papillitis and retinal oedema after the injection of tetanus antitoxin. Similar observations were made by Mason (1922) after typhus vaccination, by Bedell (1935) after vaccination against diphtheria, and by Bothman (1940). In all cases an anaphylactic reaction took the form of a state of shock followed by high fever and lightheadedness, and complete recovery ensued. Allergic papillitis was described by Lascu and Niculescu (1958) and acute optic neuritis by Gregersen (1964) immediately after smallpox vaccination. The neuritis disappeared spontaneously, but was followed 3 months later by a rapid visual loss with increasing bilateral optic atrophy and field defects resembling those seen in the case here reported.

The condition appears to be due to a disturbance of the intracranial circulation, a localized ischaemia causing endarteritis around the optic nerves. An arachnoiditis of this nature was provoked experimentally by Ito (1957) with typhus vaccine and by Onoe (1959) with antirabies vaccine. Moro (1961) produced anaphylactic reactions 
in rats with human albumin, showing vascular changes in the vessels of the retina and optic nerves.

The primary optic lesion was not recognized or observed in this case, but the history of anaphylactic shock and ensuing optic atrophy, vascular sheathing, and visual field defect indicate that this bilateral optic atrophy is due to a complication of serum sickness aroused by vaccination against common cold not previously observed (Duke-Elder, 1964).

Our view is supported by a recent virological analysis by Hornsleth and Volkert (1964), which questions the value of the usual vaccines against the common cold.

\section{Summary}

Visual loss caused by bilateral optic atrophy is described in a 55-year-old male. This atrophy is presumed to be a sequel to a primary optic neuritis provoked by an anaphylactic shock at the third injection of common cold vaccine.

\section{REFERENCES}

Bedell, A. J. (1935). J. Amer. med. Ass., 105, 1502.

Bothman, L. (1940). "Year Book of Eye, Ear, Nose and Throat", 7, 58.

Duke-Elder, S. (1964). Personal communication.

Edmund, J., and GodTfredsen, E. (1963). Acta ophthal. (Kbh.), 41, 693.

Gregersen, E. (1964). Personal communication.

Hornsleth, A., and Volkert, M. (1964). Ugeskr. Laeg., 126, 121.

ITo, H. (1957). Acta Soc. ophthal. jap., 61, 1909.

KENNEDY, F. (1938). J. nerv. ment. Dis., 88, 91.

LASCU, F., and NiCulesCU, M. (1958). Oftalmolagia (Buc.), 3, 207.

Mason, V. R. (1922). J. Amer. med. Ass., 78, 88.

MORO, F. (1961). Ann. Ottal., 87, 223.

ONOE, K. (1959). Jap. J. Ophthal., 3, 200.

Theodore, F. H., and Schlossman, A. (1958). "Ocular Allergy”, p. 380-399. Williams and Wilkins, Baltimore. 